\title{
Research on the Evaluation System of Science and Technology Innovation Ability in Jing-Jin-Ji Region*
}

\author{
Dan $\mathrm{Wu}$ \\ School of Economics and Management \\ North China University of Technology \\ Beijing, China 100144
}

\author{
Siqi Cao \\ School of Economics and Management \\ North China University of Technology \\ Beijing, China 100144
}

\begin{abstract}
This author refers to the existing literature, systematically reviews the evaluation results of regional $S \& T$ innovation capability from the aspects of evaluation connotation, evaluation index and evaluation method. The existing evaluation index design mainly adopts the qualitative analysis method, and the evaluation of regional $S \& T$ innovation ability lays more emphasis on the comprehensive and coordinated development level between science and technology innovation, economic development, social governance and ecological environment construction from the scale quantity, which is not included in the quality factor of efficiency of scientific and technological innovation. Therefore, combining the statistical analysis method and the qualitative analysis method to determine the initial index system, the author includes S\&T innovation efficiency into the evaluation system of S\&T innovation ability through the quantitative model screening, and incorporating the efficiency of scientific and technological and determines the final index system to improve the reliability and validity of the evaluation index screening, calculate regional science and technology innovation ability from the perspective of collaborative development. Taking Beijing, Tianjin and Hebei as examples, DEA model and Malmquist index model are used to calculate the S\&T innovation efficiency in Beijing, Tianjin and Hebei Province. On this basis, principal component analysis and capacity coupling degree model are used to calculate the comprehensive and coordinated development level between science and technology innovation, economic development, social governance and ecological environment construction and evaluate the scientific and technological innovation ability of Beijing-Tianjin-Hebei. The research results show that: (1) the input and output of $S \& T$ innovation in most years in BeijingTianjin-Hebei region have reached an efficient state and technological progress has been achieved. (2) The coordination degree and degree of coordinated development among scientific and technological innovation, economic development, social governance and ecological environment construction in Beijing, Tianjin and Hebei from 2009 to 2015 have been increasing year by year while the coordination degree of four system of scientific and technological innovation, economic development, social governance and ecological environment construction in Jing-Jin-Ji is decreasing year by year and degree of coordinated development shows an increasing trend except for the decrease from 2014 to 2015 . (3)The development of scientific and technological innovation, economic
\end{abstract}

*Fund Project: Social Science Fund Youth Project of Beijing (17GLC064) development, social governance and ecological environment construction system in Beijing is relatively balanced with relatively high level. It should fully maintain its own advantages, give full play to the spillover effect, share the scientific and technological achievements with Tianjin and Hebei Provinces or transfer the technology to Tianjin and Hebei Provinces for fee, and improve the structure and direction of allocation of science and technology resources in order to improve the incompatibility of the economic development, social governance and ecological environment construction within Jing-Jin-Ji region.

Keywords-Jing-Jin-Ji; scientific and technological innovation capacity; efficiency; evaluation; coordination degree; degree of coordinated development

\section{INTRODUCTION}

The Fifth Plenary Session of the 18th CPC Central Committee puts forward the five development concepts of "innovation, coordination, greenness, openness and sharing", which provides important strategic support for realizing the development goal of China during the period of "13th FiveYear Plan", solving the problems of national economy and social development in China and strengthening advantages for development. Innovative development is the top of five concepts of development, embodied in various aspects such as theoretical innovation, institutional innovation, scientific and technological innovation, and cultural innovation. The degree of coordinated development of science and technology innovation, economic development, social governance and ecological environment construction as an important link in distinguishing scientific and technological innovation ability plays an important role in promoting sustainable development of regional economy and society. Therefore, the research on the evaluation system of regional $\mathrm{S} \& \mathrm{~T}$ innovation capability has become a hot issue that scholars have long been concerned about. Therefore, the research status of evaluation system of regional $\mathrm{S} \& \mathrm{~T}$ innovation capacity is systematically combed and reviewed from the aspects of evaluation connotation, evaluation index and evaluation method by referring to the existing literature at home and abroad. Taking Jing-Jin-Ji region as an example, the scientific and technological innovation capability of JingJin-Ji is comprehensively evaluated from the perspective of coordinated development. 


\section{LITERATURE REVIEW}

As a strategic element that can directly or indirectly promote scientific and technological progress and promote economic growth in the region, science and technology resources are mainly embodied in six major categories of resources including human power, material resources, financial resources, information, organization and environment [1]. Judging from the existing research results, the evaluation of regional S \& T innovation capability can be divided into two stages: the evaluation of $S \& T$ innovation efficiency and the evaluation of comprehensive and coordinated development of S \& T innovation, economic development, social governance and eco-environment construction. Among them, 1) evaluation of regional S \& T innovation efficiency focuses on evaluating the efficiency of input and output of regional science and technology innovation and analysis of redundant input and output of regional science and technology innovation [2-9]. 2) Evaluation of comprehensive and coordinated development between scientific and technological innovation, economic development, social governance and ecological environment construction mainly evaluate the coordination of regional technological innovation and economic and social development [10-19], coordination of scientific and technological innovation and ecological environment construction [20-22], and the coordination of technological innovation, economic development, social governance and ecological environment construction [23-25].

The evaluation index system of regional science and technology innovation capacity involves scientific and technological innovation index, economic and social development index and ecological environment construction index. 1) Aiming at scientific and technological innovation index, scientific and technological financial input and scientific and technological human input are widely adopted as the index of scientific and technological input because of their quantifiability [2-9]; 2) for economic and social development indicators, the emphasis is laid on the level of economic development, industrial structure, national income level, education level, employment status and urbanization level [10-19]; 3) In view of the ecological environment construction index, the discharge of pollutants, pollution control and resources and energy stocks are highlighted [2025]. Combined with the evaluation index system of scientific and technological innovation ability, at present, the evaluation methods of regional scientific and technological innovation capabilities contain qualitative and quantitative categories. The qualitative evaluation method adopts expert consultation method to make comparative analysis of regional science and technology innovation input and output based on the index data, determine the coordination among regional innovation in science and technology, economic and social development and ecological environment construction[26-27]; quantitative evaluation method uses multi-objective decision-making model of DEA method and Malmquist index method to calculate regional science and technology innovation efficiency and assesses the coordination degree between scientific and technological innovation, economic and social development and ecological environment construction [2-9,28-34].

Judging from the existing research results, there are two deficiencies in the evaluation of $\mathrm{S} \& \mathrm{~T}$ innovation capability in the region at present: First, in the aspect of index system design, more qualitative analysis is used to determine the evaluation index based on the importance of the index and the accessibility of the data, which is subjective; Second, when evaluating the regional scientific and technical innovation capability, the scientific and technological innovation level is mainly measured from the perspective of the scale and quantity, while the efficiency and quality are ignored. To this end, the following improvements have been made in the evaluation of regional scientific and technological innovation capability: 1) In the aspect of index system design, the initial index system is determined through statistical analysis and qualitative analysis, and then the final index system is selected through quantitative model screening so as to improve the reliability and validity of evaluation index screening, and then improve the objectivity and scientificness of the evaluation results; 2) When evaluating the regional $S \& T$ innovation capability, $S \& T$ innovation efficiency is included in the calculation of $S \& T$ innovation comprehensive index, which breaks through the limitations of past research that only measure the scientific and technological levels based on scale and quantity to improve the quality level of scientific and technological innovation. On this basis, taking Jing-Jin-Ji region as the research object, this paper synthetically appraises the S\&T innovation efficiency in Jing-Jin-Ji region and coordination degree among scientific and technological innovation, economic development, social governance and ecological environment construction in Jing-Jin-Ji region.

\section{RESEARCH DESIGN}

\section{A. Evaluation of Scientific and Technological Innovation Efficiency}

1) Static efficiency evaluation: DEA method is used to calculate the regional science and technology innovation efficiency in different periods, and the calculation model can be expressed as:

$$
\begin{aligned}
& \min \left[\theta-\varepsilon\left(e^{T} s^{-}+e^{T} s^{+}\right)\right] \\
& \left\{\begin{array}{l}
\sum_{j=1}^{n} \lambda_{j} x_{i j}+s^{-}=\theta x_{i j_{0}} \\
\sum_{j=1}^{n} \lambda_{j} y_{r j}-s^{+}=y_{r j} \\
\lambda_{j} \geq 0, j=1,2, \cdots, n \\
s^{+} \geq 0, s^{-} \geq 0
\end{array}\right.
\end{aligned}
$$

In formula (1), $\theta$ is the DEA effective value of regional science and technology innovation efficiency in $j_{0}$ th period; $\varepsilon$ is infinite Archimedes; $e$ is the unit vector, $s^{-}$and $s^{+}$are slack variables, $x_{i j}$ is the index value of the $i$ th output index of scientific and technological innovation in the $j$ th period.

$y_{r j}$ is the index value of the $r$ th output index of scientific 
and technological innovation in the $j$ th period; $\lambda_{j}$ is the index weight.

According to Eq. (1), when $\theta=1$ and $s^{-}=s^{+}=0$, the efficiency of regional science and technology innovation in the $j_{0}$ th period is DEA efficient. When $\theta=1$ and $s^{-} \neq 0$ or $s^{+} \neq 0$, the efficiency of regional science and technology innovation in the $j_{0}$ th period is weak DEA efficiency. When $\theta<1$, the efficiency of regional science and technology innovation in the $j_{0}$ th period is DEA inefficient. The value of science and technology innovation efficiency calculated by this model is in the range of $[0,1]$. If the efficiency of regional science and technology innovation in different periods is equal to 1 , the advantages and disadvantages of efficiency cannot be compared. Therefore, using the superefficiency DEA model and linearly expressing the input and output of $S \& T$ innovation of evaluated unit by using the input and output of S \& T innovation of other units can solve the limitation that the value of $\mathrm{S} \& \mathrm{~T}$ innovation efficiency is limited to $[0,1]$.

2) Dynamic efficiency evaluation: The dynamic efficiency of regional science and technology innovation can be reflected by the total factor productivity change (TFPch). Under the condition of constant returns to scale, TFPch can be decomposed into Technical Efficiency Change Index (TEch) and Technical Process Change Index (TPch). When the scale returns are variable, TEch can be further decomposed into Pure Technical Efficiency Change Index (PEch) and Scale Technical Efficiency Change Index (SEch). The valuation model can be expressed as

$$
\left\{\begin{array}{l}
T F P \text { ch }=T E c h \times T P c h=P E \mathrm{ch} \times S E \mathrm{ch} \times T P c h \\
T E c h=\frac{d^{t+1}\left(x_{t+1}, y_{t+1} \mid C, S\right) / d^{t+1}\left(x_{t+1}, y_{t+1} \mid V, S\right)}{d^{t}\left(x_{t}, y_{t} \mid C, S\right) / d^{t}\left(x_{t}, y_{t} \mid V, S\right)} \times\left[\frac{d^{t+1}\left(x_{t+1}, y_{t+1} \mid V, S\right)}{d^{t}\left(x_{t}, y_{t} \mid V, S\right)}\right] \\
P E \mathrm{ch}=\frac{d^{t+1}\left(x_{t+1}, y_{t+1} \mid C, S\right) / d^{t+1}\left(x_{t+1}, y_{t+1} \mid V, S\right)}{d^{t}\left(x_{t}, y_{t} \mid C, S\right) / d^{t}\left(x_{t}, y_{t} \mid V, S\right)} \\
S E \mathrm{ch}=\frac{d^{t+1}\left(x_{t+1}, y_{t+1} \mid V, S\right)}{d^{t}\left(x_{t}, y_{t} \mid V, S\right)} \\
T P c h=\left[\frac{d_{i}^{t}\left(x_{t+1}, y_{t+1}\right)}{d_{i}^{t+1}\left(x_{t+1}, y_{t+1}\right)} \times \frac{d_{i}^{t}\left(x_{t}, y_{t}\right)}{d_{i}^{t+1}\left(x_{t}, y_{t}\right)}\right]^{\frac{1}{2}}
\end{array}\right.
$$

In (2), TFPch represents the total factor productivity change index, measuring the dynamic efficiency of scientific technological innovation in the region: when TFPch> 1 , it indicates that there is technological progress in the region; when TFPch <1, it indicates that there is a technical recession in the region; when TFPch $=1$, it indicates no change in regional technical level; Tech indicates the technical efficiency change index, which measures the relative technical efficiency change situation; and TPch indicates the technical process change index and measures the change of production technology frontier; $x$ and $y$ are input and output index of scientific and technological innovation, and $d_{i}^{t}\left(x_{t+1}, y_{t+1}\right)$ is the scientific and technological innovation efficiency of $i$ th for decision- making unit in $t+1$ th period compared with that in $t$ th period. PEch means pure technical efficiency; SEch means scale efficiency; $S$ means production possibility set; $C$ means constant returns to scale, while $V$ means variable returns for scale; $d^{t}\left(x_{t}, y_{t} \mid C, S\right)$ refers to the efficiency of scientific and technological innovation relative to $t$ period in the condition of constant $S$ production possibility set returns to scale. $d^{t}\left(x_{t}, y_{t} \mid V, S\right)$ indicates the efficiency of scientific and technological innovation relative to $t$ period under the condition that $S$ production possibility set and the returns to scale are variable.

\section{B. Evaluation of Scientific and Technological Innovation Ability}

1) Construction of comprehensive level index: The comprehensive level index of $\mathrm{S} \& \mathrm{~T}$ innovation system, economic development system, social governance system and eco-environment construction system are constructed by adopting the principal component analysis method, and the specific steps are as follows:

The first step is to standardize the evaluation index. The calculation formula of standardizing evaluation index can be expressed as

$q_{i}=\left\{\begin{array}{l}\frac{a_{i}}{\max \left\{a_{i}\right\}}, a_{i} \text { is the index that have positive contribution to the system } \\ \frac{\min \left\{a_{i}\right\}}{a_{i}}, a_{i} \text { is the index that have negative contribution to the system }\end{array}\right.$

The second step is using principal component analysis to determine the initial comprehensive development index of science and technology, economy, society and ecology. First of all, factor analysis is made to the index data of four dimensions and the principal component factor $Q_{j}=\sum_{i=1}^{n} \beta_{i} q_{i}$ is

extracted ( $\beta_{i}$ is contribution rate of the $i$ th index factor $q_{i}$ to the principal component factor $Q_{j}$ ).

Then according to the variance contribution rate of each principal component factor, the initial comprehensive development level index of science, economy, society and ecology $L_{i}\left(t-\sum_{j} \sigma_{j} Q_{j}\right.$ at the moment of $t$ is constructed respectively

(Where $\sigma_{j}$ is the variance contribution rate of the $j_{\text {th }}$ principal component factor $Q_{j}$ ). The larger the comprehensive development level index is constructed, the higher its development level is.

The third step is to adjust and determine the final comprehensive development level index of science and technology, economy, society and ecology. That is, since the principal component factor obeys the standard normal distribution the comprehensive development level 
determined according to it contains negative value. Therefore, in order to ensure the rationality and accuracy of the coordination evaluation, coordinate transformation is carried out on the initial comprehensive development level index of science, technology, economy, society and ecology, and normalized adjustment is made to the initial comprehensive development level index of the four with the maximum value of science and technology, economy, society and ecology as the divisor and then $R_{k}(t)-\frac{L_{k}(t)-H}{\max \left\{L_{*}(t)+H\right\}}$ is gotten. $R_{k}(t)$ is the final comprehensive development level index of science, economy, society or ecology at the time of the $t$. Among them, $H$ is the distance of coordinate transformation of initial comprehensive development level index. In order to ensure the comprehensive index after coordinate transformation is positive, $H=\max \left\{L_{k}(t) \mid\right\}$ is usually taken.

2) Evaluation of coordination Degree and degree of coordinated development: The capacity coupling degree model is used to calculate the coordination degree and degree of coordinated development of science and technology, economy, society and ecology. The coordination degree and degree of coordinated development of science and technology-economy-society-ecology can be expressed as:

$$
\begin{aligned}
& \left\{\begin{array}{l}
C=\left[\frac{\prod_{k=1}^{4} R_{k}(t)}{P^{4}}\right]^{\frac{1}{4}} \\
D=\sqrt{C \times P}
\end{array}\right. \\
& P=\frac{1}{4} \sum_{k=1}^{K} R_{4}(t)
\end{aligned}
$$

TABLE I.

\begin{tabular}{|c|c|c|c|c|}
\hline $\begin{array}{l}\text { Categories of } \\
\text { index }\end{array}$ & First grade index & Secondary index & $\begin{array}{c}\text { The contribution } \\
\text { direction to the } \\
\text { region }\end{array}$ & Unit \\
\hline \multirow{8}{*}{$\begin{array}{c}\text { Scientific and } \\
\text { technological } \\
\text { innovation index }\end{array}$} & $\begin{array}{l}\text { science and technology direct } \\
\text { output index }\end{array}$ & number of Patent application authorization & + & $\begin{array}{l}\text { ten thousand } \\
\text { pieces }\end{array}$ \\
\hline & \multirow{2}{*}{$\begin{array}{l}\text { science and technology indirect } \\
\text { output index }\end{array}$} & $\begin{array}{l}\text { contract amount of technology output region in } \\
\text { Technical market }\end{array}$ & + & $\begin{array}{l}100 \text { million } \\
\text { yuan }\end{array}$ \\
\hline & & new product sales revenue of High-tech industry & + & $\begin{array}{l}100 \text { million } \\
\text { yuan }\end{array}$ \\
\hline & \multirow[t]{2}{*}{ Technical human input index } & full-time equivalent of R \& D staff & + & $\begin{array}{l}\text { ten thousand } \\
\text { people per } \\
\text { year }\end{array}$ \\
\hline & & R \& D researchers of High-tech industry & + & $\begin{array}{l}\text { Ten thousand } \\
\text { people }\end{array}$ \\
\hline & \multirow{2}{*}{$\begin{array}{l}\text { input index of science and } \\
\text { technology financial resources }\end{array}$} & R \& D investment intensity & + & \\
\hline & & $\begin{array}{l}\text { internal spending of R \& D expenditure of High-tech } \\
\text { industry }\end{array}$ & + & $\begin{array}{l}100 \text { million } \\
\text { yuan }\end{array}$ \\
\hline & Technology quality index & Scientific and technological innovation efficiency & + & - \\
\hline \multirow{4}{*}{$\begin{array}{c}\text { Economic } \\
\text { development index }\end{array}$} & \multirow{2}{*}{ Economic level index } & gross regional production & + & trillion yuan \\
\hline & & The general budget revenue of the local government & + & trillion yuan \\
\hline & Economic structure index & The added value of tertiary industry & + & trillion yuan \\
\hline & Consumption level index & household consumption level & + & $\begin{array}{l}\text { ten thousand } \\
\text { yuan }\end{array}$ \\
\hline \multirow{4}{*}{$\begin{array}{l}\text { Social governance } \\
\text { level index }\end{array}$} & \multirow{2}{*}{ Population index } & permanent population at the end of the year & + & person \\
\hline & & urban population & + & person \\
\hline & & registered urban unemployment rate & - & $\%$ \\
\hline & people's living standard index & $\begin{array}{l}\text { year-end remaining of Urban and Rural residents' } \\
\text { RMB savings deposit }\end{array}$ & + & $\begin{array}{l}\text { ten thousand } \\
\text { yuan }\end{array}$ \\
\hline
\end{tabular}

EVALUATION INDEX System OF SCIENCE AND TECHNOLOGy INNOVATION ABILITY IN JING-JiN-Ji REgION 


\begin{tabular}{|c|c|c|c|c|}
\hline $\begin{array}{l}\text { Categories of } \\
\text { index }\end{array}$ & First grade index & Secondary index & $\begin{array}{c}\text { The contribution } \\
\text { direction to the } \\
\text { region }\end{array}$ & Unit \\
\hline \multirow{8}{*}{$\begin{array}{c}\text { Social governance } \\
\text { level index }\end{array}$} & \multirow{2}{*}{ education level index } & educational expenditure & + & $\begin{array}{l}\text { ten thousand } \\
\text { yuan }\end{array}$ \\
\hline & & $\begin{array}{l}\text { educated population above } 6 \text { years old } \\
\text { Number of medical and health institutions }\end{array}$ & $\begin{array}{l}+ \\
+\end{array}$ & $\begin{array}{l}\text { person } \\
\text { piece }\end{array}$ \\
\hline & Public service index & passenger volume & + & $\begin{array}{l}\text { Ten thousand } \\
\text { people }\end{array}$ \\
\hline & \multirow{3}{*}{ Residents insurance level index } & $\begin{array}{l}\text { number of Urban workers who have endowment } \\
\text { insurance }\end{array}$ & + & people \\
\hline & & $\begin{array}{l}\text { The accumulative balance of basic endowment } \\
\text { insurance }\end{array}$ & + & $\begin{array}{l}\text { ten thousand } \\
\text { yuan }\end{array}$ \\
\hline & & Unit area GDP energy consumption & - & Ton/yuan \\
\hline & Environmental binding index & total water consumption & - & ton \\
\hline & & forest coverage rate & + & $\%$ \\
\hline \multirow{4}{*}{$\begin{array}{c}\text { Ecological } \\
\text { environment } \\
\text { construction index }\end{array}$} & environmental protection index & $\begin{array}{l}\text { Local fiscal and environmental protection } \\
\text { expenditures }\end{array}$ & + & $\begin{array}{l}100 \text { million } \\
\text { yuan }\end{array}$ \\
\hline & \multirow{3}{*}{ Environmental pollution index } & Domestic garbage removal volume & - & Ten thousand \\
\hline & & chemical oxygen demand & - & \\
\hline & & sulfur dioxide emissions & - & ton \\
\hline
\end{tabular}

B. Analysis of the Evaluation Results of Science and Technology Innovation in Jing-Jin-Ji Region

1) Analysis of evaluation results of scientific and technological innovation efficiency

a) Analysis of static evaluation results: DEA model is used to calculate the science and technology innovation efficiency in Jing-Jin-Ji region from 2009 to 2015. Considering that the output of $\mathrm{S} \& \mathrm{~T}$ innovation has hysteresis effect on its input, the time lag of $\mathrm{S} \& \mathrm{~T}$ output relative to $\mathrm{S} \& \mathrm{~T}$ investment is set to be 1 year. That is to say, S \& T innovation input data is set as the data in 20092014, and scientific and technological innovation output index is set as the data in 2010-2015. Solution is made through Deap 2.1 and EMS software, and the author get the science and technology innovation efficiency in Jing-Jin-Ji in 2009-2015, as well as the output deficiency and input redundancy of technology ineffective unit as shown in "Table II" and "Table III".

TABLE II.

SCIENTIFIC AND TECHNOLOGICAL INNOVATION EFFICIENCY OF JING-JIN-JI REGION IN 2009-2015

\begin{tabular}{|c|c|c|c|c|c|}
\hline Area & Time & Overall efficiency & Technical efficiency & Scale efficiency & Status of returns to scale \\
\hline \multirow{6}{*}{ Beijing } & $2009-2010$ & 0.8475 & 0.8490 & 0.9990 & decrease progressively \\
\hline & 2010-2011 & 1.8362 & 1.0000 & 1.0000 & remain unchanged \\
\hline & 2011-2012 & 0.9251 & 0.9280 & 0.9970 & increase progressively \\
\hline & 2012-2013 & 0.9482 & 0.9510 & 0.9970 & decrease progressively \\
\hline & 2013-2014 & 1.0005 & 1.0000 & 1.0000 & remain unchanged \\
\hline & 2014-2015 & 1.2277 & 1.0000 & 1.0000 & remain unchanged \\
\hline \multirow{6}{*}{ Tianjin } & $2009-2010$ & 0.9626 & 1.0000 & 0.9630 & increase progressively \\
\hline & 2010-2011 & 0.8672 & 1.0000 & 0.8670 & increase progressively \\
\hline & 2011-2012 & 0.8904 & 0.9670 & 0.9210 & increase progressively \\
\hline & 2012-2013 & 1.1103 & 1.0000 & 1.0000 & remain unchanged \\
\hline & 2013-2014 & 0.9852 & 0.9980 & 0.9880 & decrease progressively \\
\hline & 2014-2015 & 1.0395 & 1.0000 & 1.0000 & remain unchanged \\
\hline \multirow{6}{*}{ Hebei } & $2009-2010$ & 0.9995 & 1.0000 & 1.0000 & remain unchanged \\
\hline & 2010-2011 & 0.9451 & 1.0000 & 0.9450 & increase progressively \\
\hline & 2011-2012 & 1.0787 & 1.0000 & 1.0000 & remain unchanged \\
\hline & $2012-2013$ & 0.9965 & 0.9980 & 0.9980 & increase progressively \\
\hline & 2013-2014 & 0.8676 & 0.8710 & 0.9960 & increase progressively \\
\hline & 2014-2015 & 1.0442 & 1.0000 & 1.0000 & remain unchanged \\
\hline \multirow{6}{*}{ Jing-Jin-Ji } & $2009-2010$ & 0.9604 & 0.9710 & 0.9900 & increase progressively \\
\hline & 2010-2011 & 1.2140 & 1.0000 & 1.0000 & remain unchanged \\
\hline & 2011-2012 & 0.9712 & 0.9810 & 0.9900 & increase progressively \\
\hline & 2012-2013 & 1.0089 & 1.0000 & 1.0000 & remain unchanged \\
\hline & 2013-2014 & 1.0744 & 1.0000 & 1.0000 & remain unchanged \\
\hline & 2014-2015 & 1.3091 & 1.0000 & 1.0000 & remain unchanged \\
\hline
\end{tabular}


TABLE III. OUTPUT DEFICIENCY AND INPUT REDUNDANCY OF SCIENTIFIC AND TECHNOLOGICAL INNOVATION IN JING-JIN-Ji REGION

\begin{tabular}{|c|c|c|c|c|c|c|c|c|}
\hline \multirow[b]{2}{*}{ Region } & \multirow[b]{2}{*}{ Time } & \multicolumn{3}{|c|}{ Output deficiency } & \multicolumn{4}{|c|}{ Input redundancy } \\
\hline & & $\begin{array}{c}\text { Number of } \\
\text { patent } \\
\text { application } \\
\text { authorization in } \\
\text { China (piece) }\end{array}$ & $\begin{array}{l}\text { Contract amount } \\
\text { of technology } \\
\text { output region in } \\
\text { Technical market } \\
\text { (ten thousand } \\
\text { yuan) } \\
\end{array}$ & $\begin{array}{l}\text { New product } \\
\text { sales revenue } \\
\text { of High-tech } \\
\text { industry (ten } \\
\text { thousand } \\
\text { yuan) }\end{array}$ & $\begin{array}{c}\text { Full-time } \\
\text { equivalent of } \\
R \& D \text { staff } \\
\text { (person/year) }\end{array}$ & $\begin{array}{c}\text { Full-time } \\
\text { equivalent of } \\
\text { High-tech } \\
\text { industry } R \& \\
\text { D personnel } \\
\text { (person/year) }\end{array}$ & $\begin{array}{c}R \& D \\
\text { investmen } \\
\text { t intensity } \\
(\%)\end{array}$ & $\begin{array}{c}\text { Internal } \\
\text { spending of } R \\
\& D \\
\text { expenditure of } \\
\text { High-tech } \\
\text { industry (ten } \\
\text { thousand yuan) } \\
\end{array}$ \\
\hline \multirow{3}{*}{ Beijing } & $2009-2010$ & 10091.08 & 2818202 & 2427893 & 0 & 2709.178 & 0.028 & 0 \\
\hline & 2011-2012 & 17004.83 & 1910719 & 1979367 & 0 & 1767.452 & 0 & 0 \\
\hline & $2012-2013$ & 14984.05 & 1464100 & 813476.4 & 0 & 166.734 & 0.093 & 0 \\
\hline \multirow{2}{*}{ Tianjin } & 2011-2012 & 670.67 & 225233.8 & 392077.5 & 0 & 648.01 & 0.042 & 15359.22 \\
\hline & 2013-2014 & 1546.254 & 8063.423 & 38996.49 & 0 & 583.556 & 0.128 & 17046.03 \\
\hline \multirow{2}{*}{$\begin{array}{l}\text { Hebei } \\
\text { province }\end{array}$} & $2012-2013$ & 37.011 & 106149.4 & 4058.288 & 0 & 138.816 & 0.039 & 0 \\
\hline & 2013-2014 & 2976.836 & 864770 & 400811.4 & 0 & 0 & 0 & 419.058 \\
\hline \multirow{2}{*}{ Jing-Jin-Ji } & $2009-2010$ & 10910.34 & 2903830 & 688890.6 & 0 & 3686.087 & 0 & 0 \\
\hline & 2011-2012 & 18534.57 & 529011.2 & 1602728 & 3822.858 & 1721.551 & 0 & 0 \\
\hline
\end{tabular}

As can be seen from "Table II", in addition to the sharp increase in the scientific and technological innovation efficiency in Jing-Jin-Ji region from 2010 to 2011, the scientific and technological innovation efficiency in Jing-JinJi region during 2009-2015 shows an increasing status. In 2010-2011 and 2012-2015, efficient state of technological innovation is achieved, and the efficiency values reached the high level of 1.3091 and 1.2140 in 2014-2015 and 20102011. In 2009-2012 and 2011-2012, there was a phenomenon of inefficiency in science and technology innovation. After dividing the overall efficiency into technical efficiency and scale efficiency, it can be found that scientific and technological innovation in Jing-Jin-Ji shows technical inefficiency, scale inefficiency and decreasing returns to scale of scientific and technological innovation in the two years. It can be found that the reason for technology inefficiency in Jing-Jin-Ji in 2009-2010 lies in the redundancy of science and technology human input of hightech industry and the insufficient direct and indirect science and technology output. The scale inefficiency and the increasing return on scale of the input-output of science and technology exist at the same time, which shows that Jing-JinJi failed to give full play to the advantage of increasing returns to scale, and the science and technology input with rational structure is low. Therefore, increasing the scientific and technological human and financial resources in Jing-JinJi region from 2009 to 2010 and improving the science and technology financial input and high-tech industry science and technology financial input in Jing-Jin-Ji region in 20112012 can promote efficiency.

In 2009-2010, the overall science and technology innovation efficiency level in Beijing is relatively lower than that in Jing-Jin-Ji region, but the change trend is the same as in Jing-Jin-Ji region. Both of them surged sharply in 20102011 , with a science and technology innovation efficiency of 1.8362 , surpassing that of Jing-Jin-Ji region. In addition, that in other years shows an increasing status, but the efficiency values in the same period are lower than those in Jing-Jin-Ji region. Efficiency of $\mathrm{S} \& \mathrm{~T}$ innovation is achieved since 2013 with efficiency values of 1.0005 and 1.2277 in 20132014 and 2014-2015 respectively. It can be found from decomposition of overall efficiency that technical inefficiency and scale inefficiency both exist in the year of inefficient scientific and technological innovation, of which

science and technology innovation shows decreasing returns to scale in 2009-2010 and 2012-2013. That is to say, the reason for scale inefficiency is that the investment in science and technology is too large. Scientific and technological innovation in 2011-2012 shows increasing returns to scale, so the scale inefficiency is due to the lack of a reasonable science and technology input scale. Combining with "Table 3 ", it can be found that input redundancy of science and technology financial input and science and technology human input of scientific and technological human of hightech industry in Beijing in 2009-2010 are both higher than those in 2012-2013 while the degree of input redundancy of regional science and technology financial resources and science and technology direct output are both lower than those in 2012-2013. The input redundancy in 2011-2012 occurs only in the science and technology human input of high-tech industries, and the output deficiency exist in both direct output and indirect output. Therefore, reducing the science and technology financial resources input and science and technology human input of high-tech industry in Beijing in 2009-2010 and 2012-2013 and increasing science and technology human financial input and the science and technology financial input of high-tech industry can boost the promotion of scientific and technological innovation efficiency.

In 2009-2010, the overall level of science and technology innovation efficiency in Tianjin was relatively lower than that of Beijing, and fluctuated up and down. Among them, scientific and technological innovation achieved efficiency only in 2012-2013 and 2014-2015 with the efficiency value of 1.1103 and 1.0395 respectively; in 2009-2011, coexistence of the technical inefficiency and scale inefficiency of S \& T innovation leads to overall inefficiency and the returns to scale of $\mathrm{S} \& \mathrm{~T}$ innovation input and output is increasing. That is, the inefficiency of $S \& T$ innovation in this period is due to the scarcity of input in science and technology; coexistence of the technical inefficiency and scale inefficiency of S \& T innovation in 2011-2012 leads to overall inefficiency, and the returns to scale of $\mathrm{S} \& \mathrm{~T}$ innovation input and output is increasing. Combining with "Table III", it can be found that the reason for technical inefficiency during this period lies in the redundancy of regional investment in science and technology and input in science and technology of high-tech industry and the lack of 
direct output and indirect input of science and technology. The coexistence of scale inefficiency of science and technology input and output and increasing returns to scale indicates that increasing science and technology human input in Tianjin can promote efficiency; the technical inefficiency, scale inefficiency and decreasing returns to scale of science and technology input and output exist at the same time in 2013-2014. Combining with "Table III", it can be found that during this period, input redundancy occurred in science and technology financial resources and science and technology human and financial resources in high-tech industry and output deficiency in direct and indirect output of science and technology in Tianjin. At the same time, the scale inefficiency of science and technology resource allocation and decreasing returns to scale show that reducing the input of science and technology financial resources and science and technology human and financial inputs of high-tech industry can enhance the scientific and technological innovation efficiency during the period.

In 2009-2010, the level of input-output efficiency of science and technology in Hebei Province is generally relatively low and fluctuating compared with that in Beijing. Among them, the years when output and input of science and technology is efficient are 2011-2012 and 2014-2015, with the efficiency values of 1.0787 and 1.0442 respectively, and it was close to effective state from 2009 to 2010; the inputoutput of S \& T shows scale inefficiency and the increasing returns to scale in 2010-2011, which means the scale of $S$ \& $\mathrm{T}$ investment is not enough during this period, so increasing investment in $\mathrm{S} \& \mathrm{~T}$ across the board can effectively promote S \& T input and output efficiency; in 2012-2014, technical inefficiency and scale inefficiency of science and technology input and output and increasing returns to scale exist at the same time. Combining with "Table 3", it can be found in 2012-2013, technology inefficiency of science and technology input and output is due to the input redundancy of science and technology financial resources and science and technology human resources of high-tech industry in Hebei Province and the coexistence of lack of direct and indirect science and technology output. The reason for technology inefficiency of science and technology resource allocation in 2013-2014 is due to the coexistence of input redundancy of science and technology financial input of high-tech industry and lack of direct and indirect science and technology output. In the meantime, because of the scale inefficiency of science and technology input and output and increasing returns to scale in Hebei Province during this period, increasing regional overall scientific and technological human input and the investment in science and technology of high-tech industry in 2012-2013 and increasing the input of regional science and technology human and financial resources and science and technology financial resources of high-tech industry investment in 20132014 can promote the efficiency.

Through the analysis, it can be seen that the overall scientific and technological innovation efficiency in the JingJin-Ji region is superior to the individual level of provinces and municipalities, which indicates that the input and output of scientific and technological innovation in the region is not reasonable. For example, in 2009-2010, both Beijing and Tianjin show scale inefficiency of science and technology innovation input and output, but Beijing is in a state of decreasing returns to scale while Tianjin is in a state of increasing returns to scale. Therefore, the transfer of science and technology resources from Beijing to Tianjin can simultaneously improve the scientific and technological innovation efficiency in both regions; in 2012-2013, scale inefficiency of input and output of science and technology innovation occurred in both Beijing and Hebei. However, the scale of returns in Beijing is decreasing while it is increasing in Hebei Province. The transfer of science and technology resources from Beijing to Hebei can improve the efficiency of scientific and technological innovation in both regions. In 2013-2014, scale inefficiency of input and output of science and technology innovation occurred in both Hebei and Tianjin. However, Tianjin shows a state of decreasing returns to scale while Hebei is in a state of increasing returns to scale. The transfer of science and technology resources from Tianjin to Hebei can simultaneously improve the efficiency of the two regions.

Through the decomposition of the overall efficiency, it can be seen that there is input redundancy and output deficiency in science and technology in each region of JingJin-Ji and structure of different science and technology resources allocation is also unreasonable. Therefore, adjusting the structure of science and technology resources allocation and rationally distributing scientific and technological resources input in Beijing, Tianjin and Hebei is an effective measure to improve the overall scientific and technological innovation efficiency in all provinces, municipalities, and Jing-Jin-Ji region.

b) Analysis of dynamic evaluation results: Using the Malmquist index model, this paper estimates the changes in the scientific and technological innovation efficiency of Jing-Jin-Ji from 2009 to 2015. The data selection is consistent with static evaluation. Solving with Deap 2.1 software, the overall efficiency change index, technical efficiency change index, pure technical efficiency change index, scale efficiency change index and total factor productivity change index of scientific and technological innovation in Jing-Jin-Ji from 2009 to 2015 are obtained, as shown in "Table IV". 
TABLE IV. DYNAMIC CHANGES OF SCIENCE AND TECHNOLOGY INNOVATION EFFICIENCY IN JING-JIN-JI REGION IN 2009-2015

\begin{tabular}{ccccccc}
\hline Region & Time & Effch & Tpch & Pech & Sech & Tpfch \\
\hline \multirow{6}{*}{ Beijing } & $2010-2011$ & 1.000 & 1.419 & 1.000 & 1.000 & 1.419 \\
& $2011-2012$ & 1.000 & 0.737 & 1.000 & 1.000 & 0.737 \\
& $2012-2013$ & 1.000 & 1.059 & 1.000 & 1.000 & 1.059 \\
& $2013-2014$ & 1.000 & 1.059 & 1.000 & 1.000 & 1.059 \\
& $2014-2015$ & 1.000 & 1.021 & 1.000 & 1.000 & 1.021 \\
\hline \multirow{6}{*}{ Tianjin } & $2010-2011$ & 1.000 & 1.043 & 1.000 & 1.000 & 1.043 \\
& $2011-2012$ & 1.000 & 1.101 & 1.000 & 1.000 & 1.101 \\
& $2012-2013$ & 1.000 & 1.201 & 1.000 & 1.000 & 1.201 \\
& $2013-2014$ & 1.000 & 1.092 & 1.000 & 1.000 & 1.092 \\
Hebei & $2014-2015$ & 1.000 & 1.042 & 1.000 & 1.000 & 1.042 \\
\hline \multirow{6}{*}{ Jing- } & $2010-2011$ & 1.000 & 1.149 & 1.000 & 1.000 & 1.149 \\
& $2012-2012$ & 1.000 & 1.414 & 1.000 & 1.000 & 1.414 \\
& $2013-2014$ & 1.000 & 0.878 & 1.000 & 1.000 & 0.878 \\
& $2014-2015$ & 1.000 & 0.913 & 1.000 & 1.000 & 0.913 \\
& $2010-2011$ & 1.000 & 1.201 & 1.000 & 1.000 & 1.201 \\
& $2012-2012$ & 1.000 & 0.914 & 1.000 & 1.000 & 0.914 \\
& $2013-2014$ & 1.000 & 1.102 & 1.000 & 1.000 & 1.102 \\
& $2014-2015$ & 1.000 & 1.021 & 1.000 & 1.000 & 1.021 \\
\hline \multirow{6}{*}{ Jin-Ji } & 1.042 & 1.000 & 1.000 & 1.042 \\
\hline
\end{tabular}

Effch, tpch, pech, sech and tfpch in "Table IV:" represent the overall efficiency change index, technical efficiency change index, pure technical efficiency change index, scale efficiency change index and total factor productivity change index of scientific and technological innovation respectively, of which the total factor productivity can be used to represent the current technical level, and $T F P$ ch $=P E$ ch $\times S E$ ch $\times T P C h$. If the value of technical efficiency change index and total factor productivity index is 1 , it indicates that there is no change in technical level; if the value is bigger than 1 , it indicates that the technology has been improved; if it is smaller than 1, it indicates that there is a trend of technological decline.
"Table IV" shows that the changes in Total factor productivity change index in Jing-Jin-Ji region and Beijing, Tianjin, and Hebei are mainly due to the changes in the technical efficiency change index. Among them, the technical progress in Tianjin is the most significant, with continuous technological progress achieved from 2009 to 2015 and in 2012 to 2013 it achieved the biggest degree of technical progress, with the total factor productivity change index of 1.201; then in Beijing and Jing-Jin-Ji region, technical recession only occurred in 2011-2012 and the recession degree of Beijing is bigger than that of Jing-Jin-Ji region. The main reason is that science and technology innovation efficiency in Beijing from 2011 to 2012 is lower than that in 2010-2011 and the overall efficiency decreases by 0.9111 as in "Table II". In the rest years, technological progress is achieved. The years with the highest degree of technological progress in both places are 2010-2011, with a total factor productivity change index of 1.419 and 1.201 respectively. The technical progress is relative worst in Hebei Province where technological decline occurred in 2012-2014 and the degree of decline is bigger in 2012-2013 than that in 2013-2014. In the rest years, the greatest degree of technological progress was achieved in 2011-2012, with the total factor productivity change index of 1.414 , next only to 1.419 of Beijng where the level of technological progress is largest in 2010-2011.

2) Analysis of evaluation results of scientific and technological innovation ability: "Table V" shows the coordination degree and degree of coordinated development of science and technology system, economic system, social system and ecosystem in Jing-Jin-Ji region.

TABLE V. THE COORdINATION DEGREE AND DEGREE OF COORDINATED DEVElopMENT OF SCIENCE AND TECHNOLOGY SYSTEM, ECONOMIC SYSTEM, SOCIAL SYSTEM AND ECOSYSTEM IN JING-JIN-JI REGION

\begin{tabular}{ccccccccc}
\hline \multirow{2}{*}{ year } & \multicolumn{2}{c}{ Beijing } & \multicolumn{2}{c}{ Tianjin } & \multicolumn{2}{c}{ Hebei } & \multicolumn{2}{c}{ Jing-Jin-Ji region } \\
& $\boldsymbol{C}$ & $\boldsymbol{D}$ & $\boldsymbol{C}$ & $\boldsymbol{D}$ & $\boldsymbol{C}$ & $\boldsymbol{D}$ & $\boldsymbol{C}$ & $\boldsymbol{D}$ \\
\hline $2009-2010$ & 0.7712 & 0.5654 & 0.3657 & 0.3404 & 0.7048 & 0.3913 & 0.9186 & 0.6791 \\
$2010-2011$ & 0.8558 & 0.5908 & 0.5511 & 0.4098 & 0.7828 & 0.4232 & 0.8915 & 0.6992 \\
$2011-2012$ & 0.8770 & 0.6225 & 0.6339 & 0.4584 & 0.8294 & 0.4508 & 0.8702 & 0.7349 \\
$2012-2013$ & 0.8771 & 0.6462 & 0.6949 & 0.4976 & 0.8608 & 0.4638 & 0.8449 & 0.7526 \\
$2013-2014$ & 0.8966 & 0.6751 & 0.7314 & 0.5190 & 0.8783 & 0.4771 & 0.7932 & 0.7544 \\
$2014-2015$ & 0.9173 & 0.7029 & 0.7734 & 0.5438 & 0.8977 & 0.4946 & 0.6534 & 0.7073 \\
\hline
\end{tabular}

a) Coordination degree of science-economy-societyecology: According to "Table V", the coordination degree of science and technology system economic system, social system and ecosystem in Beijing is best from 2009 to 2015, with the average value of coordination degree during the six years of 0.8658 , which is at moderate coordination level, and the coordination value is increasing year by year from 0.7712 in 2009-2015 to 0.8966 in 2013-2014, approaching a high level of coordination and then increased to 0.9173 in 2014-2015. The coordination level achieved a high level among science and technology, economy, society and ecosystems; the coordination degree of Jing-Jin-Ji region and Hebei Province is the next. The average value of coordination degree in Jing-Jin-Ji region during the six years is 0.8286 , at a moderate level of coordination.
However, the values of coordination degree show a declining trend year by year, from the high level of 0.9186 in 2009-2010 to moderate level in 2010-2014, and then dropped to the running-in coordination level of 0.6534 in 2014-2015. The average value of coordination degree in Hebei Province during the six years is 0.7734 , which is at a moderate level, and the value of coordination degree is increasing year by year from 0.7048 at lower limit of moderate coordination level in $2009-2010$ to 0.8977 in 2014-2015, approaching a high level of coordination; the coordination degree of Tianjin is the worst, with the average value of 0.6338 during the six years, at the running-in level. The value of coordination degree also increases year by year, from the low level of coordination in 2009-2011 to the running-in level in 2011-2013, and then increases to 
moderate level in 2013-2014. Based on the above analysis, it can be found that the ranking of coordination degree of science and technology system, economic system, social system and ecosystem from 2009 to 2011 is Beijing, Hebei, Jing-Jin-Ji region and Tianjin. On the whole, the overall four systems in Beijing, Hebei, and Jing-Jin-Ji region reach a moderate level of coordination, and the four systems in Tianjin are at the running-in level. The coordination values in Beijing, Tianjin and Hebei increased year by year with the highest increase in Tianjin, followed by Hebei and Beijing, while the overall coordination degree value of JingJin-Ji region shows a decreasing trend.

b) The degree of coordinated development of science, technology, economy, society and ecology: According to "Table V", from 2009 to 2015 , the degree of coordinated development of scientific and technological systems, economic systems, social systems and ecosystems in JingJin-Ji region is the best, with the mean value of coordinated development degree during the six years of 0.7212, achieving a good level of coordinated development. Except for the decrease in degree of coordinated development in 2014-2015, the degree of coordinated development of JingJin-Ji region increased gradually in 2009-2014, from the general level of coordinated development in 2009-2011 to the good level of coordinated development in 2011-2015, followed by Beijing where the average value of degree of coordinated development of science and technology system, economic system, social system and ecosystem during the six years is 0.6338 , which is at the general level of coordinated development. The value of coordinated development is increasing year by year from low level of coordinated development in 2009-2011 to the general level of coordinated development in 2011-2014 and to good level of coordinated development in 2014-2015. The degree of coordinated development of the four systems in Tianjin and Hebei is worse, with mean values of coordinated development of 0.4615 and 0.4501 in the six years respectively, all in a low level of coordinated development. However, the value of degree of coordinated development is increasing year by year. The growing rate of Tianjin during the six years $(0.2034)$ is close to twice of that in Hebei Province (0.1032). The degree of coordinated development of four systems in Tianjin increased from 0.3404 in 20092010 to 0.5438 in 2014-2015 while the coordinated development of four systems in Hebei Province increased from 0.3913 in 2009-2010 to 0.4946 in 2014-2015. Based on the above analysis, it can be seen that the ranking of degree of coordinated development of $\mathrm{S} \& \mathrm{~T}$ system, economic system, social system and ecosystem in 20092015 is Jing-Jin-Ji region, Beijing, Tianjin and Hebei. Overall, only Jing-Jin-Ji region has achieved good level of coordinated development as a whole, Beijing achieved general level, and Tianjin and Hebei are all at a low level of coordinated development and are at a low level of coordinated development in each year. In terms of changing situation, it shows an increasing trend in Beijing, Tianjin, Hebei and Jing-Jin-Ji region as a whole, with the largest increase in Tianjin, followed by Beijing, from a low level of coordinated development to the general level, and then to a good level of coordinated development, then followed by Hebei Province, and finally the Jing-Jin-Ji region from generally level to a good level of coordinated development.

Synthesizing the evaluation results of coordination degree and degree of coordinated development of science and technology system, economic system, social system, ecosystem, it is found that in 2009-2015, the coordination degree and degree of coordinated development of science and technology system, economic system, social system, ecosystem in Beijing, Tianjin, and Hebei achieves year by year increase while the coordination degree of the four systems in Tianjin is decreasing year by year. The degree of coordinated development shows an increasing trend except for the decline in 2014-2015. Through comparative analysis, it can be found that the overall coordination degree and degree of coordinated development among four systems in Jing-Jin-Ji region is better than that of Beijing, that of Beijing is superior to that of Tianjin and Hebei, and the coordination degree among the four systems in Hebei is better than that of Tianjin, but the degree of coordinated development is slightly lower than that of Tianjin. According to the analysis of complex development index of science and technology system, economic system, social system and ecosystem in Beijing, Tianjin and Hebei, the development of the four systems in Beijing is more balanced and the level is higher. The level of economic development and social development in Tianjin is weaker compare with the level of social science and technology development. Due to the relatively broad territory, Hebei Province has a relatively high social composite index. In contrast, the level of science and technology, economy and ecology development in Hebei Province is relatively low. Therefore, considering the current status of the four systems of science and technology, economy, society and ecology, Beijing should give full play to its role as a science and technology center of the capital, and give full play to the spillover effect of technology while promoting the economic, social and ecological development to promote the development in Tianjin and Hebei; Tianjin should focus on the economic and social benefits of science and technology and make full use of its scientific and technological strength to promote economic and social development. Hebei should actively introduce technology and increase investment in science and technology to promote the mutual progress in economic development and ecology construction while developing science and technology.

\section{CONCLUSION}

According to the evaluation results of scientific innovation efficiency of Jing-Jin-Ji region from 2009 to 2015 , it can be found that the input and output of science and technology innovation in most years in Jing-Jin-Ji region reach an efficient state and achieve technological progress, but at the same time there are some problems: First, the S \& $\mathrm{T}$ resources distribution in Beijing, Tianjin and Hebei is unreasonable, lead to the overall efficiency of Jing-Jin-Ji region being better than that of Beijing, Tianjin and Hebei; 
secondly, the allocation of S \& T resources in the region as a whole and in all provinces and municipalities is unreasonable and the regional science and technology financial input is relatively greater than human input, and science and technology financial input of high-tech industry is relative greater than human resources input; in addition, the direct and indirect output of $\mathrm{S} \& \mathrm{~T}$ innovation is not enough. Compared with the input of $\mathrm{S} \& \mathrm{~T}$ innovation, both the capability of independent innovation of Jing-Jin-Ji region and the industrialization of $\mathrm{S} \& \mathrm{~T}$ achievements need to be improved; furthermore, the lack of stability in scientific and technological innovation efficiency and large fluctuations in individual years lead to the phenomenon of technical recession. At the same time, from the coordinated evaluation results of scientific and technological innovation, economic development, social governance and ecological environment construction in Jing-Jin-Ji during 2009-2015, it is revealed that the development of science and technology, economy, society and ecosystems in Beijing is balanced and the level is relatively high, so it should fully maintain its own advantages and give full play to its spillover effect, sharing the achievements of science and technology with Tianjin and Hebei or transferring the technology to Tianjin and Hebei for money. In particular, it should support Hebei in view of ecological improvement technologies, so as to make use of the close relationship between science and technology, economy and society and ecology in Hebei Province to promote the coordinated development of science and technology, economy, society and ecology. At the same time, the structure and direction of science and technology resources allocation should be improved to solve the problem of incompatibility of economic, social and ecological development in Jing-Jin-Ji region.

Based on the above conclusions, this paper puts forward some countermeasures and suggestions on the evaluation of science and technology innovation capability in Jing-Jin-Ji region: (1) Conducting regular assessment on the science and technology innovation efficiency and adjusting the structure of different science and technology resources allocation in time to improve the science and technology innovation efficiency; (2) improving the level of scientific research personnel through education and personnel and encourage public innovation through taxation and state incentives to improve the quantity and quality of scientific research output; (3) promoting the construction of sharing mechanism for scientific research results among regions and the synergistic development mechanism of production, study and research, giving full play to the comparative advantage of all regions and industries and optimizing the structure of science and technology resources allocation in the region in order to realize the economic, social and ecological effects of " $1+1$ $+1>3$ " of scientific and technological progress in Jing-Jin-Ji region; (4) Expanding the areas of scientific and technological innovation and adjusting the direction of science and technology resources allocation. We should not only focus on commercial technological innovation, but also increase the scientific research investment in improving social welfare and ecological environment to promote the mutual development of science and technology, economy, society and ecology in various districts in Jing-Jin-Ji region.

\section{REFERENCES}

[1] Zhou Zhizhong. On Science and Technology Resources. Xi'an Shaanxi people education publishing house, 1999:43-50.

[2] Qi Yong, Guo Yi. Efficiency Evaluation of scientific and technological Resources Market Allocation Based on SFA Method. Science and Technology Management Research, 2015,36(3):84-91.

[3] Chen Wenshan, Gu Jinlong, Huang Wei. Research on the Relationship and Coordination between Input-Output of $\mathrm{R} \& \mathrm{D}$ Resource in China - A Case Study of Jiangsu Province. Science and Technology Management Research, 2014(21):27-31.

[4] Xu Qiaoling. Studies on the Relative Efficiency Evaluation of S \& T Input and Output - Analysis of BCC Model and SE-CCR Model Based on DEA. Science and Technology Management Research, 2014(1):66-70.

[5] Sun Xuhua, Chen Shibo, Cheng Guoqiang. Analysis of the efficiency monitor of State-owned Science and Technology Resource Allocation and its Influencing Factors Based on Malmquist Index. Forum on Science and Technology in China, 2011(3):21-27.

[6] Meng Weidong, Wang Qing. Empirical Analysis of Influencing Factors of Science and Technology Resource Allocation Efficiency in Regional Innovation System. Statistics and Decision, 2013(4):96-99.

[7] Dang Yaru, Peng Lina. Evaluation and Analysis on the development of Provincial S \& T Resource Allocation Efficiency. Science and Technology Management Research, 2012(20):81-84.

[8] Zhou Wei, Ye Chang-in. Research on the Science\&Technology Resource Allocation Efficiency in Six Central Provinces Based on Factor Analysis Model. Statistics and Decision, 2011(12):85-87.

[9] Luo Biao, Wang Xiaoping, Ji Hongmei. Research on the Science\&Technology Resource Allocation Efficiency Based on DEA Cross-Evaluation. Modern Management Science, 2011(12):35-38.

[10] Noda, Hideo. R\&D-Based Models of Economic Growth Reconsidered[J]. Information-An International Interdisciplinary Journal,2012,15(2):517-536.

[11] Beaudreau, Bernard C.,Lightfoot, H. Douglas. The physical limits to economic growth by R\&D funded innovation[J]. ENERGY,2015,84: 45-52.

[12] Moutinho, Ricardo, Au-Yong-Oliveira, Manuel,Coelho, Arnaldo. Beyond the "Innovation's Black-Box": Translating R\&D outlays into employment and economic growth[J].SOCIO-ECONOMIC PLANNING SCIENCES, 2015,50: 45-58.

[13] Huang Ying. The Relationship between Investment in Science and Technology and Economic Growth in China: 1978-2009. Times Finance, 2014(6):32-33.

[14] Zhang Zhiyou. Science and Technology Investment and Economic Growth: Nonlinearity with Thresholds. Forum on Science and Technology in China, 2014(5):32-38.

[15] Pan Fanghui, Li Cuixia, Fan Bin. Markov's regimes switching model of Fiscal science and technology investment Cycle and Business Cycle Synergies. Forum on Science and Technology in China, 2015(3):42-47.

[16] Dong Huizhong, Zhang Feng, Yin Xiuqing. A Dynamic Correlation Analysis on Science and Technology level and Low-carbon Economy Development Based on extensible Evaluation. Journal of Financial and Economic Theory, 2015(3):1-8.

[17] Kang Shaoda, Wang Jian. Studies on the interactive Effect between the Science and Technology Progress and the Development of Low Carbon Economy in Cities. Macroeconomics, 2016(8):116-122.

[18] Zhi Huawei, Du Gang, Xie Baichen. Research on Regional Lowcarbon Economic Efficiency from the Perspective of Science and Technology driving. Science \& Technology Progress and Policy, 2012,30 (3):25-31.

[19] Ma Weigang. Study on Coordinated Development of science and Technology Progress Environment, High-tech Industrialization and Economic Development Mode Transformation. Journal of industrial technical economics, 2016 (6):10-16.

[20] Xiang Li. Temporal and spatial characteristics of coordinated development of provincial science and technology innovation and 
ecological environment in China. Technology Economics, 2016,35(11):28-35.

[21] Li Dongdong, Xu Zhengliang, Zhou Huiguang. Study on the Impact of $\mathrm{S} \& \mathrm{~T}$ Investment on Regional Ecological Environment Optimization. Modern Management Science, 2013(5):63-65+71.

[22] Lu Zhaoyang. Study on the Impact of Agricultural Science and Technology Progress on Agricultural Carbon Emissions from Provincial Perspective. Studies in Science of Science, 2013,31(5):674-683.

[23] Kocsis, Imre,Kiss, Judit T. Renewable energy consumption, R\&D and GDP in European union countries[J]. Environmental Engineering And Management Journal, 2014,13(1):2825-2830.

[24] Wang Wei, Zhang Jianye, Qiao Penghua. Studies on the Coordinated Development of Regional Sci-tech Talents, Industrial Economy and Ecological Environment - Based on Panel Data of 18 Larger Cities in China. Science \& Technology Progress and Policy, 2014,31(7):37-42.

[25] Wang Haijing. An Empirical Study on the Advanced Industrial Structure, Sci-tech Innovation and Carbon Emissions in China. Marketing research, 2016(4):39-41.

[26] Sun Xijie. Analysis of Exponential Law of Science and Technology and Economy Coordinated Growth - on Paradoxes of "Exponential Growth" of Science and Technology. Studies in Science of Science, 2012, 30(6):813-819.

[27] Han Bin, Kong Jijun. Rethink on Science and Technology Innovation and Low Carbon Development in Yunnan. China Population Resources and Environment, 2014,24(3):24-26.

[28] Zhong, Wei, Yuan, Wei, Li, Susan X. The performance evaluation of regional R\&D investments in China: An application of DEA based on the first official China economic census data[J]. Omega-International Journal of Management Science,2011,29(4):447-455.

[29] Li, Wang Hong, Liang, Liang, Cook, Wade D. Measuring efficiency with products, by-products and parent-offspring relations: A conditional two-stage DEA model[J]. Omega-International Journal of Management Science,2017,68:95-104.

[30] WangBei, Liu Wei-dong,Zhang Jian-bo. Evaluation on the Efficiency for the Allocation of Science and Technology Resources in China Based on DEA Model [J]. Advances in Intelligent and Soft Computing,2012,138:125-140.

[31] Chen, Chiang-Ping, Hu, Jin-Li,Yang, Chih-Hai. Produce patents or journal articles? A cross-country comparison of R\&D productivity change[J]. SCIENTOMETRICS,2013,94(3):833-849.

[32] Lu, Wen-Min,Kweh, Qian Long,Nourani, Mohammad,Huang, FengWen. Evaluating the efficiency of dual-use technology development programs from the R\&D and socio-economic perspectives[J]. OmegaInternational Journal of Management Science,2016,62:82-92.

[33] Peng Cheng, Zheng Changde. Study on the science and technology input efficiency in China Based on DEA Two-stage Network DEA. Science \& Technology Progress and Policy, 2014,31(8):125-129.

[34] Fan Fei, Zhang Jianqing, Yang Gangqiang, et al. Study on the Spatial Spillover Effect of Regional Science and Technology Resource Allocation Efficiency under Environment Constraints. China Soft Science, 2016(4):81-80. 